\title{
An Optimality Analysis of the Phonological Processes in the Speech of Autistic Algerian Children: A Case Study
}

\author{
Meymouna Bourzeg \\ Department of Linguistics, The University of Jordan \\ Amman, Jordan \\ E-mail: bourezegmimi@gmail.com
}

Received: July 5, 2020

Accepted: August 11, 2020

Published: August 19, 2020

doi:10.5296/ijl.v12i4.17557

URL: https://doi.org/10.5296/ijl.v12i4.17557

\begin{abstract}
The current paper scrutinizes the phonological processes used by an autistic child, in Standard Arabic, via the use of a constraint-based framework of optimality theory. The data of the present study were collected through a picture-naming test. To ensure that the pictures are representative of all standard Arabic phonemes, the researcher designed a test containing 84 pictures representing three intra-word positions (initial, medial, and final). The results reveal that the autistic child grammar is characterized, mainly, with seven phonological processes: sibilant dentalization, de-emphasization, gliding, stopping, nasality spreading, final consonant deletion, and fronting. Autistic children's phonological system is stigmatized by unmarked forms. In terms of optimality theory, treating the phonological problems of autistic children requires demoting the highly ranked unmarked constraints and promoting the lowest-ranked faithfulness constraint.
\end{abstract}

Keywords: Optimality theory, Autism, Algerian children, Phonological process

\section{Introduction}

Autism is a developmental, neuropsychiatric disorder that is intensely allied with impairment in socialization, communication, and the presence of restricted and repetitive behaviors (Medical Research Council, 2001). Social impairment in autism is affected by ample factors, including gender, age, level of intellectual functioning, and language skills (Syriopoulou-Delli, Agaliotis, \& Papaefstathiou, 2016). Communication impairment, in its turn, is a patent symptom of autism. Deficiency or delay in language use and communicative gestures are the 
main attributes of such impairment. Correspondingly, autistic children have an impediment in initiating or maintaining conversations. Their language use is characterized by eccentric use of words, the use of private metaphors, and echolalia (American Psychiatric Association, 1994). Kanner (1943) believed that autistic children have certain kinds of behaviors that are characterized by high frequency and repetition in undeviating modus, this is what is referred to as restricted and repetitive behaviors.

Reviewing the works, pertaining to autism, unveiled that researchers' interest has been oriented towards examining its non-linguistic aspects including psychiatric, psychological, and educational facets. Contrariwise, stressing its linguistic aspects has received little attention (Shriberg et al., 2001; Rapin and Dunn, 2003). It was only recently that researchers have started making in-depth scrutiny of the linguistic traits of autism disorders. Documenting, assessing, and treating language system in autism is of paramount importance as it has an immense influence on children's thinking, learning, and social relationships (Mody \& Silliman, 2008; Mody et al., 2013). With regard to the type of research conducted on the relation between language and autism disorders, most studies were comparative in nature (Ramírez-Santana, Acosta-Rodríguez, \&Hernández-Expósito, 2019; Sng, Carter\& Stephenson, 2018). That is, researchers in these studies tend to shed light on the linguistic differences between autistic individuals and other groups including, but not limited to, mentally retarded persons, normally developing individuals and other informants diagnosed with different disorders. To illustrate, Bartak, Rutter, \& Cox (1975) conducted a study to assess the language disabilities of autistic Children. 49 children who have acute language disabilities were chosen as the study sample. Amidst the 49 children, 19 were classified as autistic and the other 23 children did not have clear autistic symptoms and were classified, based on their language comprehension and production complications, as having "uncomplicated developmental language disorder". Language abilities in the two groups were assessed through the use of Reynell Scales, the Peabody Picture Vocabulary Test (PPVT), and natural speech samples. The results indicated that the uncomplicated developmental language disorders group scored higher than autistic children on the PPVT scores, and the Reynell comprehension scale revealed that autistic children had a more aberrant language development than the non- autistic children.

Though a detailed explanation of all the linguistic aspects of autistic children is not the concern of the present paper, a short overview is needed as all aspects of language are interconnected. The five fields of language namely, pragmatics, semantics, syntax, morphology, and phonology have been examined with varying degrees. Unlike the other aspects of language, Pragmatic impairments have been well documented (Arunachalam \&Luyster, 2015). Williams (1994) describes the pragmatic impairments of autistic individuals as lacking the concept of "talking with". Children and adults diagnosed with autism spectrum disorders are assumed to be confronted with difficulties in understanding metaphors, indirect speech, interactional inferences, jokes, and irony (Loukusa et al., 2006, MacKay \& Shaw, 2005, Martin \& McDonald, 2004). They also experience difficulty in storytelling and selecting suitable diction (Diehl, Bennetto, \& Young, 2006; Ghaziuddin \& Leonore, 1996). Regarding semantics, its infirmities are crystallized in the difficulty of forming categories of concepts (Menuyk \& Quill, 1985). Other studies suggested that autistic individuals cannot understand the linkage among 
objects and that they use diverse plans for recalling meaning (Bernstein \& Teigerman, 1993). On the effect of autism on syntax development, researchers have dialectical views. Jarrold, Boucher \& Russell (1997), for instance, see that normal and mentally retarded children have better syntactic mastery compared to verbal autistic children. Jarrar (2015) assumes that the syntax of verbal autistic individuals does not seem to be delayed rivaled to other language domains, or non-autistic individuals with developmental delays. Previous research disclosed that the syntax of autistic children is characterized by errors in using verb tense, articles and conjunctions (Eigsti \& Bennetto, 2009), difficulty in producing questions and negation utterances (Happé \& Frith, 1996). Studies examining the morphological processing in autism are limited, and even the existing evidence is evasive (Vulchanova et al., 2013). Waterhouse \& Fein (1982) postulated that morphology is not impaired in autism; whereas, other studies suggested that morphology is not spared. Bartolucci, Pierce \& Streiner (1980) assumed that autistic children produce less grammatical morphemes, they usually use an uninflected form of verbs (Manookin, 2004), and have difficulty in using some linking words (Wing, 1996).

\section{Autism and Phonology}

As for the domain of phonology, which is the main concern of the current paper, the researcher has observed that there is a kind of disagreement in the literature reporting on phonological development in autism. Pierce and Bartolucci (1977), for instance, posited that verbal autistic children have normal phonological development. Whilst Bartak, Rutter, \& Cox (1975) believed that autistic children have delayed phonological development. Shriberg et al. (2011), in their turn, assumed that phonology within autism is damaged; however, Cleland et al. (2010) claimed that children diagnosed with autism spectrum disorders display both normal and deviant phonological processes. Autistic individuals' lack of attention to their linguistic environment is said to be the main cause of their phonological irregularities (Schoen, Paul, \& Chawarska, 2011).

Disclosing the phonological processes used by autistic individuals has been the focal concern of an ample of papers. Wolk and Edwards (1993), for instance, examined the speech of 8 years old autistic child through the use of connected speech, object naming, and delayed imitation. The results indicated that stops, nasals, and glides were present in the speech of the child; however, fricatives, affricates, and the alveolar approximant /r/ were absent. The results also revealed that autistic child grammar is characterized by certain phonological processes that are common in normal children including, but not limited to, final consonant deletion and stopping. Furthermore, the phonemic inventory of the child is characterized by a chronological mismatch. That is, later developing sounds such as /z/ and /3/ were present in his speech while earlier sounds such as $/ \mathrm{s} /$ and $/ \mathrm{J} /$ were absent; though in normally developing children, voiceless fricatives are acquired before the voiced ones. Another interesting study is the one conducted by Wolk and Giesen (2000). They have analyzed the speech of four autistic siblings through the use of object naming and spontaneous speech utterances. The results denoted that these autistic children, the three severely impaired males, display delayed phonological behavior and have abnormal patterns that seldom exist in the speech of normally developing children such as velarization and liquid frication. The speech of autistic children is most frequently stigmatized with the following phonological processes gliding, cluster reduction, and final consonant 
deletion, phoneme specific nasal emission, and initial consonant deletion (Wolk \& Brennan, 2013).

Regarding optimality theory (OT) which is the framework adopted in the present paper, it is a formal linguistic framework that analyzes the grammatical system of language (Barlow, 2001, p.242). It was first devised by the two linguists Alan Prince and Paul Smolensky in 1991 (McCarthy, 2002, p. 1). Optimality doctrine has influenced linguistic theory extensively, but its greatest impact was on phonology (Bourzeg \& Mahadin, 2020). The association between the underlying representation (input/phonemic representation) which involves unpredictable and contrastive information in the language and the surface representation (the output/ phonetic representation) which contains predictable, noncontrastive information, has been accounted for previously via the use of derivations (rules). On the contrary, optimality theory accounts for such association through constraints (Barlow \& Gierut, 1999). Constraints are both universal and violable. The ranking of these constraints differs from a language to another and from a speaker to another leading to language variations and individual differences (Prince\& Smolensky, 2004; Barlow \& Gierut, 1999; \& McCarthy, 2007). The relation between the input and the output, within the optimality theory, is mediated by GEN and EVAL. The generator (GEN) creates numerous possible candidates then the evaluator (EVAL) opts for an optimal one, the candidate that sustains the least violation of the high ranked constraints, concerning the particular ranking of constraints within a specific language (Barlow, 2001). OT makes use of tableaux to show how optimal candidates are chosen. Consider Table1.

Table 1. The optimal output of /X/ (Bourzeg \& Mahadin, 2020)

\begin{tabular}{lll}
\hline$/ \mathrm{X} /$ & $\mathrm{A}$ & $\mathrm{B}$ \\
\hline a. Candidate 1 & $!$ & \\
\hline b. Candidate 2 & & $*$ \\
\hline
\end{tabular}

\section{$\mathrm{A} \gg \mathrm{B}$}

In Table 1. The generator constructs two possible candidates: Candidate 1 and Candidate 2. The optimal candidate, which is stigmatized by the pointing hand ( $\$)$, is Candidate 2 as it satisfies the high-ranked constraint. The symbol (*) marks violation, while the symbol (!) marks fatal violations. Constraint ranking is described via the diacritic (>) (Jouini, 2015).

A plethora of studies has applied a constraint-based approach to dissect the phonological processes used by children. Yasin \& Mahadin (2018), for instance, examined the speech of a Jordanian child with phonological disorders through the use of optimality theory. The results revealed that the speech of the child is characterized by eight error patterns, namely: "final consonant deletion, stopping, cluster reduction, gliding, prevocalic voicing, glottal replacement, unstressed syllable deletion, and vocalization' (p.3). The paper uses optimality theory as a guideline to correct the child's phonological errors through the reranking of constraints, videlicet the lower-ranked constraints are promoted, and the other highly ranked constraints are demoted. Barlow (2001) examined the speech of 3.9 years old child with phonological disorders. The results indicated that the speech of the child is characterized by unmarked formulae that are ascribed to high- ranking markedness constraints *FRICATIVES 
and *LIQUID-[r]. Some intra- and inter-word variations were present in the child's talk signaling an equal ranking of constraints. As-Sammer (2016) examined the speech of three Iraqi children with high functioning autism. The prominent processes used by these children are "homorganic substitution, glottalization, frication, nasalization, fronting, flapping, dentalization, velarization, palatalization, pharyngealization, uvularization, and vowel heightening'" (p.34 \& 35). According to this study, the lowest faithfulness constraints defeat markedness constraints. Following the same line of thoughts, Azieb and Mahadin (2018) have identified five phonological processes used by normally developing Algerian children viz. reduplication, syllable deletion, cluster simplification, final consonant deletion, and vowel epenthesis. The results indicate that these phonological processes completely disappear at the age of five years as a consequence of constraint reranking.

Reviewing the literature pertaining to autistic children shows that the phonological processes applied in standard Arabic by Algerian autistic children require further studies as it has been studied previously neither through the optimality theory nor through any other phonological approach. The present paper aims at filling this gap by laying out the phonological processes used by Algerian autistic children; meanwhile, proposing a treatment via the use of a constraint-based approach to autistic children's errors.

\section{Methodology}

The data of the present study were collected from a six-year-old single male autistic child whose mother tongue is Algerian Arabic. He was marked for neither cognitive nor health delays. Following the same reasoning of Abou-Elsaad, Baz, \& El-Banna, (2009) and Lefebvre et al. (2008), who designed speech tests to evaluate children's phonological production, the researcher designed a picture-naming test including 84 pictures representing all the 28 standard Arabic consonants in three intra-word positions initial, medial and final environment (see appendix). Five Algerian Ph.D. Students who are studying at the University of Jordan were asked to validate the test and to answer the following questions:

1) Are the selected pictures common and culturally suitable for Algerian children?

2) Do the selected photos represent the intended words? If the answer is no, mark the pictures that do not represent the tested words.

3) Do you have any comments on the test?

Modifications to the test were made according to the examiners' comments. As the autistic child refused to interact with the researcher, a child-mother interaction was needed. In such an interaction the mother was given ample of instructions including the use of normal pitch and motivating her child to speak in standard Arabic. If the child does not recognize the word, which is represented through a picture, mothers were asked to give contextual and semantic cues such as posing questions, using gestures, and voice mimicking. If after all the previous attempts the child still did not spot the tested word, the mother was asked to make use of delayed imitation. The mother-child interaction was audio recorded in a quiet room, the total duration of the audios is 20 mins. Neither the perceptual ability of the children nor the duration they took to recognize the words was measured as they are not the concern of the present paper. 


\section{Al Macrothink}

International Journal of Linguistics

ISSN 1948-5425

2020, Vol. 12, No. 4

After listening to the audios, the researcher deleted some items for they were too unintelligible to analyze accurately. The data was transcribed using IPA symbols), then analyzed via the constraint-based approach.

\section{Results and Discussion}

\subsection{Sibilant Dentalization}

There are four sibilants in standard Arabic / $/$ /, /z/, /s/, /s $\mathrm{s}^{\mathrm{z}}$ (Greenberg, Kemmer \& Denning, 1990). According to Ladefoged and Maddieson (1996), "the principal source of the [sibilant] sound is the turbulent airstream produced when the jet of air created by the dental or alveolar constriction strikes the teeth, which form an obstacle downstream from the constriction itself" (p.145). The informant of the current study articulates sibilant segments with a more anterior tongue using $/ \theta /$ and / $/$ / consonants, this process is referred to as sibilant dentalization. Data bearing on this process are provided (1).

(1)

\begin{tabular}{|c|c|c|}
\hline Standard Arabic & Child's form & Gloss \\
\hline /xofa:j/ & {$[\mathrm{fa}: \theta]$} & bat \\
\hline /s'afa:ra/ & [Өafaja] & whistle \\
\hline /Rasad/ & [Pa $\theta \mathrm{ad}]$ & lion \\
\hline /fames/ & {$[\theta \operatorname{am} \theta]$} & sun \\
\hline /zarafa/ & [ðajafa] & giraffe \\
\hline
\end{tabular}

A constraint-based account of sibilant dentalization requires fetching two constraints to the fore*[sibilant] and IDENT-IO (place). *[sibilant] bans sibilant segments (Dekkers, Leeuw, \& Weijer, 2000), and is a highly ranked constraint that eclipses IDENT-IO (place). The latter constraint forces corresponding input place features to surface in output form (Kager, 2004).

Table 2. Autistic child's ouptimal output of /xofa: $/$

\begin{tabular}{lll}
\hline$/$ xofa: $\int /$ 'bat' & $*[$ sibilant $]$ & IDENT-IO (place) \\
\hline a. xofa $\int$ & $* !$ & \\
\hline b. ${ }^{*}$ xofa: $\theta$ & & $*$ \\
\hline
\end{tabular}

*[sibilant] $>>$ IDENT-IO (place)

The optimal candidate that wins the conflict is candidate (b) as it satisfies the high ranked constraint *[sibilant]. Candidate (a) is precluded in that it fatally violates *[sibilant].

\subsection{De-Emphasization}

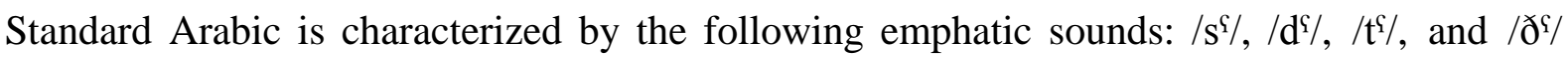
which are produced with a retracted tongue into the pharynx (Dyson \&Amayreh, 2000). Their non-emphatic counterparts are /s/, /d/, /t/ and /ð/. De-emphasization refers to the phonological process through which speakers supplant an emphatic sound by its non-emphatic equivalent, in 


\section{Macrothink}

International Journal of Linguistics

ISSN 1948-5425

2020, Vol. 12, No. 4

this case, the emphatic phoneme evades its secondary articulation (Yaceen \& Mahadin, 2018). The following instances (2) exemplify de-emphasization process in the speech of the autistic child.

(2)

\begin{tabular}{|c|c|c|}
\hline Standard Arabic & Child's form & Gloss \\
\hline /d'ifdaS/ & [difda] & frog \\
\hline /bayd / & [bayd] & eggs \\
\hline /balo:t/ & [balo:t] & oak \\
\hline /qit'a:r/ & [kita:y] & train \\
\hline
\end{tabular}

Optimality analysis of de-emphasization process might be reached through the use of three constraints *EMPHATIC, RTR-LEF, T and MAX-IO (+RTR). *EMPHATIC is the highest-ranked constraint in the proposed hierarchy. It bans emphatic sounds $/ \mathrm{s}^{\mathrm{q}} /, / \mathrm{d}^{\mathrm{q}} /, \mathrm{t}^{\mathrm{\varsigma}} /$, and $/ ð$ / from surfacing in the output form (Yaceen \& Mahadin, 2018). *EMPHATIC dominates RTR-LEFT constraint which requires [RTR], retracted tongue root, to be aligned initially in a word (McCarthy 1997, p. 235). MAX-IO (+RTR) is the least ranked constraint in the autistic child's grammar that necessitates each [+RTR] to be present in the output (McCarthy 1997, p. 235). Tableau (3), underneath, exemplifies how the autistic child deemphasizes the word /balo:t $\%$.*

Table 3. Autistic child's optimal candidate of /balout $\mathrm{t} /$ oak

\begin{tabular}{llll}
\hline /balo: $\mathrm{t}^{\mathrm{s} /}$ oak & $*$ EMPHATIC & RTR-LEFT & MAX-IO(+RTR) \\
\hline a. balo:t & & & $*$ \\
\hline b. balo: $\mathrm{t}^{\mathrm{s}}$ & $* !$ & $*$ & $*$ \\
\hline c. balo: $\mathrm{t}^{\mathrm{s}}$ & $* !$ & & \\
\hline
\end{tabular}

*EMPHATIC >> RTR-LEFT >> MAX-IO (+RTR)

In child's grammar, candidate (a) is the optimal candidate as it fulfills the highly ranked constraints *EMPHATIC and RTR-LEFT. Candidate (b) and (c) are ruled out because they fatally violate *EMPHATIC.

\subsection{Gliding}

Gliding refers to the process through which speakers subrogate /r/, /l/ with /w/, /j/, respectively (Weiss, Gordon, \& Lillywhite, 1987). It is a common phonological process that characterizes the speech of normally developing children and continues beyond the age of five years (Pena-Brooks \& Hegde, 2007). The six years autistic child exhibits the same phonological behavior, in that he substitutes /r/ for /j/. The following instances (3) are a case in a point. 


\section{1) Macrothink}

(3)

$\begin{array}{lll}\text { Standard Arabic } & \text { Child's form } & \text { Gloss } \\ \text { /ðira:ৎ/ } & \text { [ðij a:ৎ }] & \text { arm } \\ \text { /ðora/ } & \text { [ðoja/] } & \text { corn } \\ \text { /da:ira/ } & \text { [Daija] } & \text { circle } \\ \text { /mibra:t/ } & \text { [mibmibja:] } & \text { sharpener } \\ \text { /3azar / } & \text { [zaðaj] } & \text { carrots }\end{array}$

The process of gliding could be accounted for via optimality theory by positing four constraints. $*_{\mathrm{r}}$ and $*$ [dor] ban $/ \mathrm{r} /$ and dorsal phonemes from surfacing in the output form, respectively (Barlow, 2001; Shooshtaryzadeh, 2015). MAX (liquid) requires each liquid in the underlying form to appear in the output (Mkochi, 2007). DEP C, in its turn, compels input consonants to be present in the output (Heck et al., 2002). The proposed ranking of constraint together with tableau (4) illustrates how the optimal constraint/zaðaj/ is present in the autistic child's grammar.

Table 4. Autistic child's optimal output of the candidate /zazar/

\begin{tabular}{lcccc}
\hline /zazar/ & $* \mathrm{r}$ & $*[$ dor $]$ & MAX (liquid) & DEP C \\
\hline a. zaðar & $* !$ & & & \\
\hline b. zaðaj $^{2}$ & $!$ & $*$ & $!$ \\
$*$ r $>$ * [dor] $>>$ MAX (liquid) $>>$ DEP C & &
\end{tabular}

Candidate (b) is the optimal candidate as it sustain faithfulness to the high ranked constraint, *r, candidate (a) is ruled out as it fatally violates this constraint.

\subsection{Stopping}

Stopping refers to fricative or affricate substitution with stops. In the word / timsa: $\mathrm{h} /$, for instance, which surfaces as /ta: $\hbar /$ the fricative /s/ is substituted by the stop/ t/ ( notice here that the autistic child deletes the first syllable of the word). Data evincing this situation are presented (4)

(4)

\begin{tabular}{|c|c|c|}
\hline Standard Arabic & Child's form & Gloss \\
\hline /yira:?/ & [qila: ] & glue \\
\hline ha :fila/ & [hadi:la] & bus \\
\hline /yaza:1/ & [qada:] & deer \\
\hline /timsa:h/ & [ta: $\hbar$ ] & crocodile \\
\hline
\end{tabular}




\section{Ml Macrothink}

International Journal of Linguistics

ISSN 1948-5425

2020, Vol. 12, No. 4

Constraint-based analysis of stopping requires the presence of three constraints IDENT-IO, *FRICATIVE and MAX-IO. IDENT-IO [+/-continuant] is a faithfulness constraint that preserves input continuant feature in the output form. IDENT-IO [+/-continuant] is dominated by the highly ranked constraint *FRICATIVE which interdicts fricative segments from surfacing in the output forms (Barlow \& Gierut, 1999; 1488). The least ranked constraint is MAX-IO which prohibits deletion.

Table 5. Autistic children's optimal candidate of /ha:fila/

\begin{tabular}{|c|c|c|c|}
\hline /ha:fila/ & *FRICATIVE & IDENT-IO [+/-continuant]. & MAX-IO \\
\hline a. hafi:la & $* !$ & & $*$ \\
\hline b. ћa :fila & $* !$ & & \\
\hline c. hadi:la & & $!$ & * \\
\hline
\end{tabular}

*FRICATIVE $>>$ IDENT-IO [+/-continuant] >> MAX-IO

Candidate (c) is the optimal candidate for it does not sustain violation of the high ranked constraint *FRICATIVE, unlike candidates (a) and (b).

\subsection{Nasality Spreading}

Nasal segments' nasality, $/ \mathrm{m} /$ and $/ \mathrm{n} /$ in standard Arabic, may spread to other elements in intra-word position resulting in nasalized vowels and consonants, this process is referred to as nasality spreading. Though this process is not common, yet it is present in the speech of the autistic child. The collected data (5) illustrate the point.

$\begin{array}{lll}\text { Standard Arabic } & \text { Child's form } & \text { Gloss } \\ \text { /Rarnab/ } & \text { /Parnãm/ } & \text { rabbit } \\ \text { /Sinab/ } & \text { /Yinãm/ } & \text { grap } \\ \text { /mawz/ } & \text { /mãw̃/ } & \text { bananas }\end{array}$

In terms of optimality theory, nasality spreading could be explained by positing four constraints. First, the constraint Sequence ([+nasal], [-nasal], [+spread-glottis]), which is also referred to as $*$ [+nasal] h0 [-nasal], coerces nasal spreading (Albro, 2005). Second, the constraint cooccurring (Rime [+nasal]) allows nasal segments in coda position (Albro, 2005). Finally, the constraints Survived (Labial) and Survived ([+nasal]) allows labials and nasals, respectively (Stemberger \& Bernhardt, 1997). The proposed constraint hierarchy with tableau (6) elucidates how the optimal candidate (a), /Rarnãm/, wins the competition.

Table 6. Autistic children's optimal candidate of / Parnab/

\begin{tabular}{lllll}
\hline /Rarnab/ & $*[+$ nasal]h0[-nasal] & (Rime[+nasal] $)$ & SUR([+nasal] $)$ & SUR(Labial) \\
\hline a. $/$ /arnãm/ & & & & $*$ \\
\hline b. /Parnam/ & $* !$ & & $!$ & $*$ \\
\hline c. Parnab/ & $!$ & $!$ & \\
\hline
\end{tabular}

$*[+$ nasal $]$ h0 $[-$ nasal $]>>($ Rime $[+$ nasal $])>>$ SUR $([+$ nasal $])>>$ SUR(Labial $)$ 


\subsection{Final Consonant Deletion}

Final consonant deletion process is a common phonological process that is present in the speech of normally and non-developing children. This process, commonly, targets syllables of the form CVC and leads to the production of the unmarked form CV because the constraint *CODA is highly ranked in the child's grammar (Barlow and Gierut, 1999). Interestingly, this constraint is high ranked in the grammar of autistic children. CV syllables production results from the interaction between ${ }^{*}$ CODA and MAX which sustain faithfulness to the input form (Barlow \& Gierut, 1999). Instances exemplifying coda deletion are offered (6).

(6)

\begin{tabular}{|c|c|c|}
\hline Standard Arabic & Child's form & Gloss \\
\hline /d'ifdaS/ & [difda] & frog \\
\hline /tamer/ & [tam] & dates \\
\hline / tofa:h/ & [toda:] & apple \\
\hline /PiOna:n/ & [PiOna:] & two \\
\hline
\end{tabular}

To account for consonant deletion in terms of optimality theory, the researcher proposed the following hierarchy*CODA > MAX. The present hierarchy together with Table 7 illustrate how the candidate/tam/ surfaces as the optimal candidate in autistic child grammar.

Table 7. Autistic children's optimal candidates of /tamer/

\begin{tabular}{lll}
\hline /tamer/ & $*$ CODA & MAX \\
\hline a. $/$ tamer/ & $* !$ & \\
\hline b. $\% /$ tam/ & & $*$ \\
\hline
\end{tabular}

*CODA $>$ MAX

\subsection{Fronting}

The mechanism through which velar or palatal segments are substituted with alveolar ones is referred to as fronting. For instance in the example /kita:b/ the child substitutes the palatal sound $/ \mathrm{k} /$ with the alveolar sound $/ \mathrm{t} /$. The following examples (7) exhibit some instances of fronting in the speech of autistic children.

$\begin{array}{lll}\text { Standard Arabic } & \text { Child's form } & \text { Gloss } \\ \text { /kita:b/ } & \text { [ita:b] } & \text { book } \\ \text { /qird/ } & \text { [kid ] } & \text { monkey } \\ \text { /korsi/ } & {[\text { to } \theta \mathrm{i}]} & \text { chair } \\ \text { /qonfoð/ } & \text { [konfod] } & \text { urchin }\end{array}$


An optimality account for fronting in autistic children necessitates the presence of * [dor] which outranks *COMPLEX that evades consonant cluster (McCarthy \& Prince, 1993). IDENT-PLACE is the lowest ranked constraint in the proposed hierarchy. Table 8 shows the mechanism through which the optimal candidate /kid / wins the competition.

Table 8. Autistic children optimal output of /qird/

\begin{tabular}{llll}
\hline /qird/ & $*[$ dor $]$ & $*$ COMPLEX & IDENT-PLACE \\
\hline a. /qird/ & $* !$ & & \\
\hline b. /kird/ & & $!$ & $*$ \\
\hline c. $*$ /kid / & & $*$ \\
\hline
\end{tabular}

\section{Conclusion}

The present study reveals that the speech of autistic child is characterized mainly with seven phonological processes, namely sibilant dentalization, de-emphasization, gliding, stopping, nasality spreading, final consonant deletion, and fronting. The analysis of the speech of autistic children via the use of optimality theory would pave the way for treatment programs wherein pathologists are required to re-rank the proposed constraints. That is, demoting the markedness constraints and promoting the faithfulness ones by introducing marked structures. The current paper has a number of limitations which need to be considered. The sample size comes at the fore of these limitations. Hopefully, future studies will enlarge the sample size and examine the applicability of optimality theory in capturing inter variability and longitudinal change in autistic children's speech production. Another limitation of the present study is that the researcher did not have a direct contact with the study informant since the period wherein the present work was conducted coincides with COVID-19 pandemic era.

\section{References}

Abou-Elsaad, T., Baz, H., \& El-Banna, M. (2009). Developing an articulation test for Arabic-speaking school-age children. Folia Phoniatrica et Logopaedica, 61(5), 275-282. https://doi.org/10.1159/000235650

Albro, D. M. (2005). Studies in Computational Optimality Theory, with Special Reference to the Phonological System of Malagasy. Unpublished doctoral dissertation, University of California, Los Angeles.

American Psychiatric Association. (1994). Diagnostic and statistical manual of mental disorders: DSM-IV [Internet] (4th ed.). Washington, D. C.: American Psychiatric Association.

Arunachalam, S., \& Luyster, R. J. (2015). The integrity of lexical acquisition mechanisms in autism spectrum disorders: A research review. Autism Research, 9(8), 810-828. https://doi.org/10.1002/aur.1590

As-Sammer, M. A. (2016). Consonantal Interaction in the Speech of Iraqi Children with High -Functioning Autism: Evidence from Generative Phonology. Doctoral dissertation, Al-Mustansyriah University, Baghdad, Iraq. 
Azieb, S., \& Mahadin, S. R. (2018). An Optimality Analysis of Syllable-based Processes in the Speech of Normal Algerian Arabic-Speaking Children. The Jordanian Association for Educational Sciences, Jordanian Education Journal, 3(3), 27-47. https://doi.org/10.46515/2060-003-003-014

Barlow, J. A. (2001). Case Study: Optimality Theory and the Assessment and Treatment of Phonological Disorders. Language, Speech, and Hearing Services in Schools, 32(4), 242-256. https://doi.org/10.1044/0161-1461(2001/022)

Barlow, J. A., \& Gierut, J. A. (1999). Optimality theory in phonological acquisition. Journal of Speech, Language, and Hearing Research: JSLHR, 42(6), 1482-1498. https://doi.org/10.1044/jslhr.4206.1482

Bartak, L., Rutter, M., \& Cox, A. (1975). A Comparative Study of Infantile Autism and Specific Developmental Receptive Language Disorder: I. the Children. The British Journal of Psychiatry, 126(2), 127-145. https://doi.org/10.1192/bjp.126.2.127

Bartolucci, G., Pierce, S. G., \& Streiner, D. (1980). Cross-sectional studies of grammatical morphemes in autistic and mentally retarded children. Journal of Autism and Developmental Disorders, 10, 39-50. https://doi.org/10.1007/BF02408431

Bernstein, D. K., \& Tiegerman, E. (1993). Language and Communication Disorders in Children (3rd ed.). New York: Macmillan Publishers Company.

Bourzeg, M., \& Mahadin, R. S. (2020). On the Moraic Weight Representation of Geminates in Taguinian Algerian Arabic. International Journal of Linguistics, 12, 83-97. https://doi.org/10.5296/ijl.v12i2.16648

Cleland, J., Gibbon, F. E., Peppe, S. J. E., O’Hare, A., \& Rutherford, M. (2010). Phonetic and phonological errors in children with high functioning autism and Asperger syndrome. International Journal of Speech-Language Pathology, 12, 69-76. https://doi.org/10.3109/17549500903469980

Dekkers, J., Leeuw, F. V., \& Weijer, J. V. (2000). Optimality theory: phonology, syntax, and acquisition. Developmental Disorders, 26, 59-86.

Diehl, J. J., Bennetto, L., \& Young, E. C. (2006). Story recall and narrative coherence of high-functioning children with autism spectrum disorders. Journal of Abnormal Child Psychology, 34(1), 83-98. https://doi.org/10.1007/s10802-005-9003-x

Dyson, A., \& Amayreh, M. (2000). Phonological Errors and Sound Changes in Arabic-Speaking Children. Clinical Linguistics \& Phonetics, 14, 79-109. https://doi.org/10.1080/026992000298850

Eigsti, I., \& Bennetto, L. (2009). Grammaticality judgments in autism: deviance or delay. Journal of child language, 36(5), 999-1021. https://doi.org/10.1017/S0305000909009362

Ghaziuddin, M., \& Gerstein, L. (1996). Pedantic speaking style differentiatesAasperger syndrome from high-functioning autism. Journal of Autism and Developmental Disorders, 26, 585-595. https://doi.org/10.1007/BF02172348 


\section{Ml Macrothink}

International Journal of Linguistics

ISSN 1948-5425

2020, Vol. 12, No. 4

Greenberg, J. H., Kemmer, S., \& Denning, K. M. (1990). On language: Selected writings of Joseph H. Greenberg. Stanford, CA: Stanford University Press.

Happé, F., \& Frith, U. (1996). The neuropsychology of autism. Brain: A Journal of Neurology, 119(4), 1377-1400. https://doi.org/10.1093/brain/119.4.1377

Heck, F., Mueller, G., Vogel, R., Fischer, S. F., Vikner, S., \& Schmid, T. (2002). On the Nature of the Input In Optimality Theory. The Linguistic Revie, 19, 345-376. https://doi.org/10.1515/tlir.2002.003

Jarrar, H. (2015). Language acquisition in children with autism in the Arab world: evidence from processes of phonology, semantics, syntax, and pragmatics. Doctoral dissertation, Goldsmiths, University of London, Britain.

Jarrold, C., Boucher, J., \& Russell, J. (1997). Language profiles in children with autism: Theoretical and methodological implications. Autism: Journal of Research and Practice, 1, 57-76. https://doi.org/10.1177/1362361397011007

Jouini, M. (2015). On the Bimoraicity of Tunisian Arabic Open Monosyllables: A Moraic Optimality-Theoretic Approach. International Journal of Humanities and Cultural Studies, 2(3), 454-470.

Kager, R. (2004). Optimality Theory (2nd ed.). Cambridge: Cambridge University Press.

Kanner, L. (1943). Autistic disturbances of affective contact. Acta Paedopsychiatrica, 35(4), 100-136.

Ladefoged, P., \& Maddieson, I. (1996). The sounds of the world's languages. Oxford: Black-well.

Lefebvre, P., Girard, C., Desrosiers, K., Trudeau, N., \& Sutton, A. (2008). Phonological awareness tasks for French-speaking preschoolers [Tâches de mesure de la conscience phonologique chez les enfants d'âge préscolaire francophones]. Canadian Journal of Speech-Language Pathology and Audiology, 32(6), 158-168.

Loukusa, S., Leinonen, E., Kuusikko, S., Jussila, K., Mattila, M.-L., Ryder, N., et al.. (2006). Use of context in pragmatic language comprehension by children with Asperger syndrome or high-functioning autism. Journal of Autism and Developmental Disorders, 37(6), 1049-1059. https://doi.org/10.1007/s10803-006-0247-2

MacKay, G., \& Shaw, A. (2005). A comparative study of figurative language in children with autistic spectrum disorders. Child Language Teaching and Therapy, 20(1), 13-32. https://doi.org/10.1191/0265659004ct261oa

Manookin, M. B. (2004). A formal semantic analysis of autistic language: the quantification hypothesis. Department of Linguistics, Brigham Young University.

Martin, I., \& McDonald, S. (2004). An exploration of causes of non-literal language problems in individuals with Asperger syndrome. Journal of Autism and Developmental Disorders, 34(3), 311-328. https://doi.org/10.1023/B:JADD.0000029553.52889.15 
McCarthy, J. J. (1997). Process-Specific Constraints in Optimality Theory. Linguistic Inquiry, 28, 231-251.

McCarthy, J. J. (2002). A thematic guide to optimality theory. Cambridge: Cambridge University Press. https://doi.org/10.1017/CBO9780511613333

McCarthy, J. J. (2007). What Is Optimality Theory?. Language and Linguistics Compass, 1, 260-291. https://doi.org/10.1111/j.1749-818X.2007.00018.x

McCarthy, J. J., \& Prince, A. (1993). Generalized Alignment. In G. Booij, \& J. Van Marle (Eds.), Yearbook of Morphology. Yearbook of Morphology, Springer, Dordrecht. https://doi.org/10.1007/978-94-017-3712-8_4

Menyuk, P., \& Quill, K. (1985). Semantic problems in autistic children. In E. Schopler, \& G. Mesibov (Eds.), Communication Problems in Autism. New York: Plenum Press. https://doi.org/10.1007/978-1-4757-4806-2_8

Mkochi, W. (2008). Liquid/glide zero alternation in Chitonga: an optimality analysis. Humanit (Zomba), 21, 72-86.

Mody, M., \& Silliman, E. R. (2008). Brain, behavior, and learning in language and reading disorders. New York: Guilford Press.

Mody, M., Manoach, D. S., Guenther, F. H., Kenet, T., Bruno, K. A., McDougle, C. J., \& Stigler, K. A. (2013). Speech and language in autism spectrum disorder: a view through the lens of behavior and brain imaging. Neuropsychiatry, 3(2), 223-232. https://doi.org/10.2217/npy.13.19

Pena-Brooks, A., \& Hegde, M. (2007). Assessment and treatment of articulation and phonological disorders in children (2nd ed.). Austin, TX: pro-ed.

Pierce, S., \& Bartolucci, G. (1977). A syntactic investigation of verbal autistic, mentally retarded, and normal children. Journal of Autism and Childhood Schizophrenia, 7(2), 121-134. https://doi.org/10.1007/BF01537724

Prince, A., \& Smolensky, P. (2004). Optimality Theory: Constraint Interaction in Generative Grammar. Malden: Blackwell Publishing. https://doi.org/10.1002/9780470759400

Ramírez-Santana, G., Acosta-Rodríguez, V. M., \& Hernández-Expóstio, S. (2019). A comparative study of language phenotypes in Autism Spectrum Disorder and Specific Language Impairment. Psicothema, 31(4), 437-442.

Rapin, I., \& Dunn, M. (2003). Update on the language disorders of individuals on the autistic $\begin{array}{llll}\text { spectrum. Brain and Development, } & \text { 166-172. }\end{array}$ https://doi.org/10.1016/S0387-7604(02)00191-2

Schoen, E., Paul, R., \& Chawarska, K. (2011). Phonology and vocal behavior in toddlers with autism spectrum disorders. Autism Research, 4(3), 177-188. https://doi.org/10.1002/aur.183 
Shooshtaryzadeh, F. (2015). Optimality Theory and Assessment of Developing and Disordered Phonologies. Journal of Indian Speech Language and Hearing Association, 19, 13-20. https://doi.org/10.4103/0974-2131.185975

Shriberg, L. D., Paul, R., Black, L. M., \& Van Santen, J. P. (2011). The Hypothesis of Apraxia of Speech in Children with Autism Spectrum Disorder. Journal of Autism and Developmental Disorders, 41(4), 405-426. https://doi.org/10.1007/s10803-010-1117-5

Shriberg, L., Paul, R., McSweeney, J., Klin, A., Cohen, D., \& Volkmar, F. (2001). Speech and prosody characteristics of adolescents and adults with high functioning autism and Asperger syndrome. Journal of Speech, Language and Hearing Research, 44, 1097-1115. https://doi.org/10.1044/1092-4388(2001/087)

Sng, C. Y., Carter, M., \& Stephenson, J. (2018). A systematic review of the comparative pragmatic differences in conversational skills of individuals with autism. Autism \& Developmental Language Impairments.

Stemberger, J. P., \& Bernhardt, B. H. (1997). Optimality Theory. In M. Ball, \& R. Kent (Eds.), The new phonologies (pp. 211-245). San Diego, CA: Singular Publishing Group.

Syriopoulou-Delli, C. K., Agaliotis, L., \& Papaefstathiou, E. (2016). Social Skills Characteristics of Students with Autism Spectrum Disorder. International Journal of Developmental Disabilities, 64(1), 35-44. https://doi.org/10.1080/20473869.2016.1219101

Vulchanova, M., Talcott, J. B., Vulchanov, V., Stankova, M., \& Eshuis, H. (2013). Morphology in autism spectrum disorders: local processing bias and language. Cognitive neuropsychology, 29(7-8), 584-600. https://doi.org/10.1080/02643294.2012.762350

Waterhouse, L., \& Fein, C. (1982). Language skills in developmentally disabled children. Brain and Language, 15, 307-333. https://doi.org/10.1016/0093-934X(82)90062-1

Weiss, C. E., Gordon, M. E., \& Lillywhite, H. S. (1987). Clinical Management of Articulatory and Phonologic Disorders. Philadelphia: Lippincott Williams \& Wilkins.

Williams, D. (1994). Somebody Somewhere. London: Transworld Publishers.

Wolk, L., \& Brennan, C. (2013). Phonological investigation of speech sound errors in children with autism spectrum disorders. Speech, Language and Hearing, 16(4), 239-246. https://doi.org/10.1179/2050572813Y.0000000020

Wolk, L., \& Edwards, M. L. (1993). The emerging phonological system of an autistic child. Journal of Communication Disorders, 26(3), 161-177. https://doi.org/10.1016/0021-9924(93)90006-V

Wolk, L., \& Giesen, J. (2000). A phonological investigation of four siblings with childhood autism. Journal of Communication Disorders, 33(5), 371-389. https://doi.org/10.1016/S0021-9924(00)00021-6

Yaseen, M. S., \& Mahadin, R. S. (2018). An Optimality Analysis and Treatment of Phonological Disorders in the Speech of Jordanian Children: A Case Study. International Journal of Linguistics, 10, 1-20. https://doi.org/10.5296/ijl.v10i5.12615 


\section{Appendix}

Appendix 1. The designed test

\begin{tabular}{|c|c|c|c|}
\hline consonant & Initial & Medial & Final \\
\hline$/ \mathrm{S} /$ & /Pasad/ lion & $/$ faPr/ mouse & /ma: ?/ water \\
\hline$/ \mathrm{b} /$ & / ba:b/ door & /mibra:t/ sharpener & /Parnab/ rabbit \\
\hline$/ \mathrm{t} /$ & /tofa:ha/ apple & /kita:b/ book & /bayt/ house \\
\hline$/ \theta /$ & /Өala:ja/ refrigerator & /PiOna:n/ two & $/ \mathrm{mo} \theta \mathrm{ala} \theta /$ triangle \\
\hline $\mid 3 /$ & /zamal/ camel & / Jazara/ tree & $/ \theta$ alz/ snow \\
\hline$/ \hbar /$ & /hima:r/donkey & / s'ahen/dish & /mifta:h/ key \\
\hline$|x|$ & /xofa:f/ bat & /naxla/palm & /mat tax $^{\mathrm{S}}$ kitchen \\
\hline$/ \mathrm{d} /$ & /di:k/ rooster & /hadiya/ gift & /yad/ hand \\
\hline /ð/ & /ðora/ corn & /Poðon/ ear & /qonfod/ urchin \\
\hline$/ \mathrm{r} /$ & /roma:n/pomegranate & /korsi:/ chair & /tamer/dates \\
\hline $\mid \mathrm{z} /$ & /zarafa/ giraffe & /zazar/ carrots & /xobz/ bread \\
\hline /s/ & /sa:Ya/ watch & /timsa: $\hbar /$ crocodile & /d $\mathrm{d}^{\mathrm{irs}} /$ tooth \\
\hline $\mid \mathrm{g} /$ & / James/ sun & /fara:Ja/ butterfly & / So J/ nest \\
\hline$/ \mathrm{s}^{\mathrm{s}} /$ & /s $\mathrm{s}$ afa:ra/ whistle & /Gosfo:r/ bird & /qami:s $\mathrm{s}^{\mathrm{S}}$ shirt \\
\hline$/ \mathrm{d}^{\mathrm{f}} /$ & /difdaS/ frog & /xod`a:r/ vegetables & /bayd ${ }^{\mathrm{S}} /$ eggs \\
\hline$/ \mathrm{t}^{\mathrm{S}} /$ & $/ \mathrm{t}^{\mathrm{S}} \mathrm{a}:$ ?ira/ airplain & /mit'raqa/hammer & /balout /oak \\
\hline $\mid \mathrm{Z}^{\mathrm{h}} /$ & /z $\mathrm{z}^{\complement}$ aref/ envelope & /naz ${ }^{\complement}$ ara/ eyeglasses & /hifz $\mathrm{h}^{\mathrm{q}}$ memorization \\
\hline$/ \mathrm{S} /$ & /Sinab/grap & /miliaqa/spoon & /ð ira:G/ arm \\
\hline$/ \mathrm{\gamma} /$ & /yaza:1/ deer & /babaya:?/ parrot & /s'amey/glue \\
\hline /f/ & /fosta:n/dress & /ha:fila/ bus & /xaru:f/ sheep \\
\hline /q/ & /qird/ monkey & /miqas $\mathrm{q} /$ scissor & /sa:q/ leg \\
\hline$/ \mathrm{k} /$ & /kaleb/ dog & /samaka/fish & / Jawek/ thorn \\
\hline$/ 1 /$ & /laymu:n/ lemon & /qalb/ heart & /bas'al/ onions \\
\hline$/ \mathrm{m} /$ & /mawz/ bananas & /namir/ tiger & /Salam/flag \\
\hline$/ \mathrm{n} /$ & /nahla/ bee & /Panf/ nose & /mi:za:n/ scale \\
\hline$/ \mathrm{h} /$ & /ha:tif/ telephone & /mohariz/ clown & /monabih/alarm \\
\hline /w/ & /ward/ flowers & /xawx/ peach & /dalew/ bucket \\
\hline /j / & /jad/ hand & /xija:r/ cucumber & / $\mathrm{a} a \mathrm{j} /$ tea \\
\hline
\end{tabular}

\section{Copyrights}

Copyright for this article is retained by the author(s), with first publication rights granted to the journal.

This is an open-access article distributed under the terms and conditions of the Creative Commons Attribution license (http://creativecommons.org/licenses/by/4.0/) 